\title{
Aproximación a los procesos de capacitación/formación de los trabajadores siderúrgicos en SOMISA (1960-1966) ${ }^{1}$
}

\author{
Martín Pablo C. Gabiniz \\ Universidad Nacional Rosario - \\ Núcleo Estudios del Trabajo \\ gabinizmartin@yahoo.com.ar
}

\begin{abstract}
Resumen
La Sociedad Mixta Siderurgia Argentina (SOMISA), comienza su producción tras el decisivo impulso de Estado Nacional al proyecto del Gral. M. N. Savio a comienzos de la década de 1960. Partiendo del rol estratégico que para el proceso de industrialización nacional tuvo la instalación de la primera planta siderúrgica a ciclo integral, aislamos uno de los problemas necesarios para garantizar un funcionamiento óptimo: el de los procesos de capacitación/formación de su mano de obra. Observamos las diferentes estrategias implementadas por la empresa para capacitar a su personal, entre la puesta en funcionamiento de su planta industrial en noviembre de 1960, y el fin de su primer expansión productiva en julio de 1966. Rescatamos la influencia de los principales preceptos de la teoría desarrollista, así como el rol del capital trasnacional en estos procesos.

La necesidad de contar con un personal lo suficientemente calificado para lograr la calidad y el crecimiento que implicaban los trabajos propuestos, ha sido una cuestión de importante consideración en los documentos que dan cuenta de la planificación de esta industria, en los que contiene la mirada empresaria, como en la apropiación que los trabajadores hacen en su identificación con la empresa. Consideramos significativo aportar al conocimiento sobre estos procesos, para desentrañar el funcionamiento de una de las empresas más emblemáticas en el sector siderúrgico del país.
\end{abstract}

Palabras Clave: SOMISA - Industrialización - Formación /Capacitación -Trabajadores.

\begin{abstract}
:
The Joint Venture Steel Argentina (SOMISA), began production after the decisive impulse the National State gave to the project of Gen. M. N. Savio in the early 1960s. Based on the strategic role for national industrialization process that the installation of the first integrated cycle steel plant had, we remmarck one of the problems needed to ensure optimal operation:
\end{abstract}

1 Una versión preliminar de este artículo fue presentada en el II Worshop, Historia de las relaciones laborales en la Argentina del Siglo XX, Rosario, 23 y 24 de Agosto de 2012.

GABINIZ, Martín Pablo C., "Aproximación a los procesos de capacitación/formación de los trabajadores siderúrgicos en SOMISA (1960-1966)", en Avances del Cesor, Año X, No 10, 2013, pp. 35-52. 
the training process / training of its workforce. We noted the different strategies implemented by the company to train its staff, including the commissioning of the plant in November 1960, and the end of its first expansion of production in July 1966. We pointed out the influence of the main precepts of development theory and the role of transnational capital in these processes. The need to have enough qualified staff to achieve quality and growth involving the proposed work has been an important issue of consideration in the documents that shows the planning of this industry, which contains the business look, as in the appropriation that workers do in their identification with the company. We find significant contribution to the knowledge about these processes, to unravel the workings of one of the most iconic companies in the steel sector in the country. Key Words: SOMISA - Industrialisation - Training / Training-Workers.

\section{Introducción}

La profundización del procesos sustitutivo de importaciones a partir de la incorporación de industrias básicas a la estructura productiva interna, tuvo uno de sus más sobresalientes momentos con la instalación y puesta en marcha de la planta Gral. Manuel Savio, inaugurada en noviembre de 1960. Durante su primer lustro de existencia la primera unidad productiva siderúrgica a ciclo integral, permitió un crecimiento vertiginoso de la producción sectorial posibilitando su consolidación en el concierto del proceso de industrialización. En este marco el porcentaje de acero crudo se incrementó en un 163,50\%, mientras que entre 1959 y 1963 la producción siderúrgica representó el 57\% del total de la expansión del producto bruto industrial. ${ }^{2} \mathrm{El}$ aumento en términos absolutos y relativos del sector siderúrgico estuvo jalonado por el cumplimiento de las metas productivas de Sociedad Mixta Siderurgia Argentina. ${ }^{3}$

2 Uno de los mayores déficits en la producción sectorial, se ubicaba en la primera fase del procesos productivo siderúrgico, generado una marcada dependencia de las exportaciones para la posterior laminación. Respecto del incremento que significó la producción de la Planta General Savio en este sentido, podemos observar el trabajo de economía comparada de AUDINO, Patricia; SETTIMI, Stella Maris; TOHMÉ, Fernando. La Influencia de la Teoría del Desarrollo en las Políticas Económica en las Décadas de 1950 y 1960[en línea]: Los Casos de Argentina y Brasil, [Buenos Aires]: Centro de Documentación e Información del Ministerio de Economía y Finanzas Públicas, 2001. Formato PDF, Pp. 28. <http: //cdi.mecon.gov.ar/biblo/doclec/aaep/99/thome_settimi_audino_pd.> [Consulta: 7 de Julio de 2012]. Mientras que las influencias de las ramas productivas con una composición más alta de capital constante en el concierto de las modificaciones del proceso de industrialización nacional, podemos identificarla a partir del trabajo de; PERALTA RAMOS, Mónica: La Economía Política Argentina. Poder y Clases Sociales, 1930-2006, Fondo de Cultura Económico, Buenos Aires, 2007, pp. 412.

3 A partir de ahora SOMISA. 
Las transformaciones iniciadas en el sector fueron simultáneas a las reformas introducidas en otros prioritarios para las políticas públicas: la química pesada, la producción energética, la industria automotriz, la celulosa, el aumento de la producción petrolera, y la modernización de la estructura del transporte. ${ }^{4}$ El vertiginoso crecimiento económico de fines de las décadas de 1950 y comienzo de la siguiente, debe vincularse al impulso otorgado por el Estado Nacional a las inversiones productivas, influenciadas por los principales preceptos de la teoría desarrollista.

Por lo tanto, con el objetivo de acelerar el proceso de industrialización, el Congreso Nacional promulgó afines de 1958 las leyes de Radicación de Capitales Extranjeros, $N^{\circ}$ 14.780 y de Promoción Industrial, $\mathrm{N}^{\circ}$ 14.781. En el sector siderúrgico la sanción de la ley 15.801 de enero de 1961, modificaba el articulado de la 'Ley Savio' No 12987, afectando directamente la conformación de la Siderúrgica Mixta como su relación con las empresas de acabado de la producción y con la sanción del decreto 5.038/61 se promovió la intervención de los capitales privados en este sector industrial. ${ }^{5}$

En el particular contexto de los inicios productivos de la primera unidad siderúrgica a ciclo integral, nos proponemos reconstruir las alternativas con las que se concretaron los procesos de capacitación/formación del personal siderúrgico. La relativa ausencia de personal nacional, con la suficiente calificación para llevar adelante los trabajos propuestos, convierte a estos primeros años en un período particularmente interesante para observar el desenvolvimiento de estos procesos. El decisivo impulso del Estado nacional al 'proyecto Savio', como la amplia participación del capital trasnacional, incidieron decisivamente en el desenvolvimiento productivo de la planta industrial.

Debemos mencionar que el problema de la capacitación de los trabajadores en la Siderúrgica Estatal se inserta dentro de los desafíos que trajo aparejada esta segunda etapa del proceso sustitutivo de importaciones. La efectiva incorporación de industrias pesadas al

4 Respecto de estos procesos hay un amplio acuerdo en la literatura general sobre el período, ver; CORTÉS CONDE, Roberto, La Economía Política de la Argentina en el Siglo XX, Edhsa, Buenos Aires, 2005, pp. 353; ROMERO, Luis Alberto, Breve historia contemporánea de la Argentina, Edhsa, Buenos Aires, 2006, 2da edición; TORRES, Juan Carlos y DE RIZ, Lilian, "Argentina desde 1946", en BETHELL, Leslie (editor), Historia de la América Latina, , Crítica, Barcelona, 2001.

5 Para un análisis de las modificaciones propiciadas por el conjunto de esta legislación, se pueden seguir los trabajos de ASPIAZU, Daniel; BASUALDO, Eduardo; KULFAS, Martín. La industria siderúrgica en Argentina y Brasil durante las últimas décadas, [Buenos Aires]: Informe a la Federación de Trabajadores de la Industria y Afines de la Confederación Nacional de Trabajadores Argentinos (FETIA-CTA), Diciembre de 2005. Formato PDF, pp. 178. <http://www.flacaso.org.ar/uploaded_files/ Publicaciones/271_AYTE_La.Industria.Siderurgíca.en.Argetina.y.Brazil.Pdf $>$. [Consulta: 5 mayo de 2012]. KASMAN, Romina, "Siderurgia y desarrollo económico 1958-1962: Sector Público y Privado en Torno al Plan Siderúrgico, ¿relaciones de suma 0?”, X Jornadas Inter-escuelas / Departamentos de Historia, Rosario, del 20 al 23 de septiembre de 2005. 
mercado local, para impulsar el proceso de industrialización, tuvo variadas consecuencias, entre los que se ubican la modernización de los equipamientos y maquinarias aportadas por el capital trasnacional. La apuesta al sector siderúrgico, como un viejo anhelo de las ideas desarrollistas del peronismo, tuvo su concreción durante el corto período del gobierno de A. Frondizi (1958 - 1964). La participación de diversas empresas internacionales en la concreción del proyecto industrialista de Gral. Savio, destacándose las de capital Norteamericano, y la creación de un marco legal para su intervención en las ya mencionadas ramas productivas y de servicios, son a nuestros entender las orientaciones que tendrá este proceso. En ese marco comprendemos las necesidades de capacitar a los trabajadores industriales, para lograr y profundizar el desarrollo de un sector productivo clave para impulsar los procesos de industrialización.

A partir de considerar la significativa participación de estos dos actores, el Estado Nacional y el capital trasnacional, avanzamos en reconstruir las diferentes estrategias empresarias para dotar de calificación al personal. Tomamos el período que comprenden los seis ejercicios económicos contables que van desde la inauguración oficial de la planta industrial -26 de noviembre de 1960 - hasta la finalización de su primera expansión productiva en junio - julio de $1966 .{ }^{6}$

La integración del proceso productivo siderúrgico en una sola planta industrial, con la incorporación de nuevas maquinarias así como de novedosos procesos productivos parciales, implicaron también desconocidos procesos de trabajo, para los que eran necesarios un original tipo de trabajador siderúrgico. Por lo tanto, delinear los procesos de capacitación que conformaron a los primeros 'somiseros', es relevante para el campo de la historia empresaria como para la de los trabajadores.

Por un lado nos permite observar las políticas de una empresa que hasta mediados de la década del 1970 -momento que pierde preponderancia a manos de sector privado- se ubicaba en la base productiva de la rama y era el sustento del proceso de acumulación de las fracciones industriales dominantes ${ }^{7}$. Mientras que en relación a la historia de los trabajadores, habilita a pensar que rol juega la capacitación y la paulatina conformación de un mercado

6 En el decimonoveno ejercicio económico- contable, bajo el título "Comentarios del Presidente", se considera terminada la primera etapa en la expansión de la Planta Gral. Savio, SOMISA, Memorias y Balances, 1965 - 1966, Sociedad Mixta Siderúrgica Argentina, Buenos Aires, 1976.

7 BASUALDO, Eduardo M., Estudios de Historia Económica Argentina: desde mediados del Siglo XX a la actualidad, -1era Ed-, Siglo XXI, Buenos Aires, 2006 “....La importancia de la empresas estatales radicaba en que se ubicaban en la base productiva y eran el sustento del proceso de acumulación de las fracciones industriales dominantes, como es el caso de SOMISA en la elaboración de acero o YPF en la producción de combustible. Las empresas estatales y las de la burguesía nacional eran las que exhibían los requerimientos de empleo más elevados...” p. 86. 
interno de trabajo en una empresa de gran magnitud, en los procesos de identificación de los trabajadores con la gestión estatal de la siderúrgica. ${ }^{8}$

Para lograr este objetivo abordamos documentos que dan cuenta de la planificación de la empresa -"Plan Siderúrgico Nacional" y "Ley Savio" - como de su desarrollo productivo -"Memorias y Balances"-, y un conjunto de registros de construcción oral realizados junto con los trabajadores. ${ }^{9}$ Confrontamos también estos documentos con las opiniones vertidas por el Tte. Gral. Pedro Francisco Castiñeiras, quien fuera presidente de Sociedad Mixta Siderurgia Argentina desde el $1^{\circ}$ de julio de 1955 hasta el 31 de octubre de 1971. ${ }^{10}$ Este influyente personaje dentro de SOMISA, escribió en 1972 "Esto Lo Hicieron Los Argentinos", en el que hace una encendida defensa de la empresa, de sus gestiones al enfrente de la misma, así como del Plan Siderúrgico Nacional. ${ }^{11}$

Respecto de las fuentes de construcción oral, estas tienen la característica de construcción colectiva que incide en su conformación, a partir de una particular relación entre el

8 Respecto de los mercados internos de trabajo; DOERING, Peter B., PIORE, Michael, J, Mercados Internos de trabajo y análisis laboral, Ministerio de Trabajo y Seguridad Social de España, España; 1985. O el clásico estudio de sociología del trabajo de BURAWOY, Michael, El consentimiento en la producción. Los cambios del proceso productivo en el capitalismo monopolista, Ministerio de Trabajo y Seguridad Social de España, España, 1989.

9 "A pesar que las entrevistas fueron realizadas entre nueve y catorce años después de efectivizada la privatización, en noviembre de 1991, una de las características que estructuran y organizan los relatos de los trabajadores es la sensación de 'ruptura' entre la experiencia transitada durante la gestión estatal y la actual gestión privada de la empresa." GABINIZ, Martín, SOMISA: La construcción de la Primer Planta Siderúrgica Integrada y los Procesos de Capacitación - Formación de su Personal, Seminario Regional de la carrera del Profesorado en Historia, Facultad de Humanidades y Artes, Universidad Nacional de Rosario, Rosario, 2009, p. 65. Para un tratamiento sistemático y profundo sobre el impacto que provocó el proceso de privatización y reconversión productiva en el colectivo de trabajadores de la planta industrial, desde la antropología social, se puede recurrir a la investigación de SOUL, Julia, Los Unos y los Otros, la fractura que persiste. Reconversión productiva e identidades colectivas en la ex SOMISA actual Siderar, Tesina de grado para optar por la Licenciatura en Antropología Sociocultural, dirigida por Rodríguez Gloria, Universidad Nacional de Rosario, Rosario, 2002.

10 Pedro Francisco Castiñeiras fue una figura destacada dentro de la corriente de militares que defendieron la necesidad de otorgarle, desde el Estado Nacional, un impulso definitivo a la industrialización. Había asumido como director del departamento de Producción en la conformación de la Dirección General de Fabricaciones Militares, y tras las presiones sufridas a comienzo de la década de 1950 para afiliarse al partido peronista, fue pasado a retiro en 1954. Con la llegada del nuevo gobierno fue restituido otorgándosele la dirección de la empresa.

11 CASTIÑEIRAS, Pedro Francisco, Esto Lo Hicieron Los Argentinos, SOMISA, Buenos Aires, 1972. 
investigador y sus sujetos/objeto de investigación. ${ }^{12} \mathrm{~A}$ pesar de las diferencias apreciables en términos de las trayectorias laborales individuales de los entrevistados, surgieron consideraciones que pueden ser conceptualizadas como núcleos problemáticos comunes. Sobre la base de éstos, pretendemos realizar una elaboración que está orientada por los propósitos que Lutz Niethammer le adjudica a la historia oral al conceptualizarla como una técnica específica de investigación contemporánea; la exploración de determinados campos fragmentarios para los que no hay o no es accesible otros tipos de documentos de transmisión, como la posibilidad de ampliar la concepción del pasado más inmediato y de su elaboración sociocultural como historia, revirtiendo sobre la compresión de la historia en general. ${ }^{13}$

\section{Planificando la siderurgia: el proyecto Savio y la capacitación del personal de SOMISA}

Retomamos las principales proyecciones del Plan Siderúrgico Nacional (PSN), en lo referido a la capacitación/formación de la mano de obra. ${ }^{14}$ Entendemos que el despegue productivo de la planta industrial estuvo orientado por estas planificaciones, reflejando su vigencia.

A grandes rasgos, la propuesta de industrialización integrada y presentada por el Gral. Savio se asentó sobre la base de los estudios realizados por la empresa norteamericana Armnco S. A., bajo los lineamientos del industrialismo, la defensa nacional y la subsidiaridad del estado. ${ }^{15}$ En ella se avanzaba con la planificación concreta de la planta industrial. Espe-

12 AGUILA, Gabriela y VIANO, Cristina, "Las voces del conflicto: en defensa de la historia oral", en GODOY, Cristina (compiladora) Historiografía y memoria colectiva. Tiempos y territorios, Miño y Dávila, Bs. As. /Madrid, 2002.

13 NIETHAMMER, Lutz, “¿Para qué sirve la historia oral?” en, Historia Oral, ACEVES, Jorge (compilador) Instituto de Investigaciones J. M. Luís Mora, México, 1993.

14 Para este análisis retomamos las consideraciones sobre el Plan Siderúrgico Nacional del trabajo de LESSER, Ricardo y PANAÍA, Marta, "Las Estrategias Militares Frente al Proceso de Industrialización" en, LESSER, Ricardo; PANAIA, Marta; SKUPCH, Pedro, Estudio sobre los orígenes del peronismo / 2, Siglo XXI, Buenos Aires, 1975. El Plan Siderúrgico Nacional es considerado como uno de los Planes de Movilización Industrial (PMI), presentados por la corporación militar en la década de 1940, en respuesta a la etapa de evolución tecnológica del ejército, y a los requerimientos de la fracción industrialista de la burguesía nacional. Se estableció una relación de continuidad tanto con los proyectos de reforma puestos en práctica para las fábricas militares, como para el resto de los Planes de Movilización Industrial formulados por Sanguinetti (1946); Catalano (1943). Respecto del resto de los Planes de Movilización Industrial, el Plan Siderúrgico Nacional es el que más se acercaba a un consenso en su concreción, siendo el único cuyos lineamientos fueron retomamos en el proceso de industrialización.

15 Ídem, p. 4.

40 
cíficamente en "El Estudio Técnico Económico De Acero Semiterminado En La República Argentina", se resumió el asesoramiento aportado a la Dirección General de Fabricaciones Militares (DGFM) para expandir la producción. ${ }^{16}$ Allí partiendo de algunas consideraciones básicas, se detallaban los diferentes elementos que conformaron la unidad industrial, para describir el tipo y la forma en que será realizada la inversión. Se diagramaban a la vez los costos para llevar adelante las operaciones, junto con el estudio estimativo del personal requerido para cada puesto, las alternativas sobre su adiestramiento y se proponía una dirección técnica permanente para las operaciones.

Este estudio formó parte del "Convenio Sobre Trabajos Preparatorios Para La Constitución De La Sociedad Anónima Mixta", firmado por la Dirección General de Fabricaciones Militares junto a las empresas siderúrgicas accionistas que participaban del proyecto, estas ofrecieron a la Armnco S. A. para hacerse cargo de la dirección técnica como del asesoramiento global de los trabajos a realizar. En el "Convenio" se estipulaba que: "Armnco Argentina S. A. suscribe este convenio en un doble carácter: ${ }^{17}$ Por una parte, como contratista de la dirección técnica de la futura Sociedad Anónima Mixta Siderurgia Argentina, comprometiéndose a efectuar ahora parte de los trabajos de esta dirección técnica, la que en su totalidad comprende: a) La preparación de planos y estudios, supervisión de la instalación y supervisión de la puesta en marcha. Este trabajo se denominará Dirección Técnica de

16 La Dirección General de Fabricaciones Militares (DGFM) fue el organismo encargado de impulsar el desarrollo de las industrias químicas y metalúrgicas en el período de posguerra, y surgió como resultado de la maduración de las ideas favorables al desarrollo industrial en el seno del ejército. Su creación fue promovida en el año 1938 a instancias del Gral. Savio, quién había asumido dos años antes la dirección de Fabricaciones Militares. En 1941 la sanción en de la ley №12709 le da una forma definitiva respetando los principales objetivos con los que se había ideado: completar los planes castrenses de instalación de material bélico, organizar el país para la defensa en el aspecto industrial, y promover la explotación de materias primas básicas para la industria nacional. Así la dirección se propuso alentar una mayor diversificación en la estructura económica del país mediante la explotación de recursos naturales, y el afianzamiento de las industrias químicas y metalúrgicas básicas. Este extracto es una elaboración propia a partir de BELINI, Carlos, "La Dirección General de Fabricaciones Militares y su papel en la industrialización de posguerra (1941-1958)", en ROUGIER, Marcelo (compilador) Políticas de promoción y estrategias empresarias en la industrias argentina, Ediciones Cooperativas, Buenos Aires, 2007.

17 La referencia al doble carácter de la Armnco dentro del Sociedad Mixta tenía que ver con la realización de otro convenio acordado por la empresa y la Dirección General de Fabricaciones Militares, anulado por un acta complementaria de 22/II/1946. Según este convenio la empresa norteamericana pasa a formar parte de la Sociedad Mixta en carácter de accionistas, "Convenio Básico Para La Constitución De La Sociedad Anónima Mixta con Armnco Argentina S. A. Como Núcleo Para Elaborar Chapas y Planchas de Acero", SAVIO, Manuel Nicolás, "Plan Siderúrgico Nacional". Obra del General Manuel Nicolás Savio, Sociedad Mixta Siderúrgica Argentina, Buenos Aires, 1973. 
Proyecto e Instalación. b) La dirección técnica de la operación de la planta una vez puesta en marcha. Este trabajo se denominará Dirección Técnica de Operación. ${ }^{18}$

Las primeras menciones sobre la formación/capacitación del personal siderúrgico son propias del 'Estudio Técnico Económico', en su capítulo específico, “Adiestramiento del Personal". Compuesto por un breve texto, el capítulo se completa con una planilla donde se abordó la relación entre los puestos previstos para el desarrollo de la producción continua y los años de experiencia necesaria para su normal desenvolvimiento. Extraemos dos fragmentos demostrativos del texto, luego nos dedicamos al análisis de la planilla.

...durante el período inicial... será preciso, indudablemente, emplear más gente de la que se indica en la planilla, de manera que transcurridos unos meses puedan efectuarse una selección entre el personal obrero... puestos directivos que durante un tiempo bastante largo deberán ser ocupados por técnicos extranjeros especializados... habrá que traer al país unos 30 o 37 hombres, los cuales permanecerán en la planta por períodos que varían de 6 meses a varios años, según la rapidez con que el personal argentino pueda absorber la instrucción que le sea impartida... podría adelantarse algo en lo que se refiere al adiestramiento del personal, seleccionando y enviando a Estados Unidos cierto número de técnicos argentinos destinados a ocupar puestos directivos en la planta... Armnco Argentina S. A. tomaría las disposiciones necesarias para que tales técnicos reciban un adiestramiento especial en lo concerniente a las distintas operaciones de una planta siderúrgica... cuando la planta inicie sus operaciones, estos empleados directivos tendrán una idea más cabal de sus tareas, y podrán colaborar con el adiestramiento de personal que ocupará puestos de menor responsabilidad. ...Armnco Argentina S.A. prestará así mismo su colaboración en la provisión de los técnicos extranjeros necesarios... para la puesta en marcha de la planta... casi la totalidad de los puestos podrá ser desempeñado competentemente por argentinos dentro de un período de 5 a10 años... ${ }^{19}$

Las estrategias acordadas con la Armnco para suplir la ausencia de personal capacitado, implicaron una notoria intervención de la empresa norteamericana en los momentos iniciales, con el objetivo de llevar adelante la producción y capacitar gradualmente a los siderúrgicos nacionales. En este proceso el acento estuvo puesto en el personal técnico para su instrucción como jerárquicos, mientras que los puestos de menor jerarquía fueron relegados a capacitarse en el momento mismo de la producción. La selección del personal quedó también en manos de la trasnacional, que de ésta manera se reservó las decisiones estratégicas sobre el perfil de los empleados que tendrían a cargo la dirección del proceso productivo.

En "Personal Para Operaciones", se establecieron los puestos y la cantidad del personal para operar las unidades de producción..$^{20}$ El cálculo estaba realizado sobre una estima-

18 Ídem, p. 313.

19 Ídem, p. 6.

20 SAVIO, Manuel Nicolás, "Plan Siderúrgico...", Op. Cit., pp. 174-175. 
ción de 24hs., especificando la experiencia media necesaria para que cada operario pueda desenvolverse eficientemente. Se agregaba el detalle de aquellos puestos ocupados por el personal extranjero perteneciente a la Armnco S. A.

Según la planilla técnica, los puestos claves en la jefatura del proceso productivo estaban reservados a los extranjeros, las superintendencias -puestos de mayor jerarquía en la unidad productiva- de las unidades de mayor importancia, Altos Hornos y hornos Siemens Martín, son un claro ejemplo. A la vez, en cada unidad productiva se previó un mínimo de puestos ocuparse por personal foráneo, destacándose la sección de mantenimiento y reparaciones donde su presencia ascendía al $40 \%$ sobre la totalidad de los puestos. Suponemos que se relacionaba con los requerimientos de versatilidad y experiencia laboral del personal que los ocupaba, para afrontar en el menor tiempo posible las paradas de máquinas y su funcionamiento en el mayor grado de eficiencia. Si bien la cantidad de puestos reservados al personal extranjero solo llegaba al 10\% del total (entre 30 y 37 sobre 307 a 308 previstos), eran los puestos de mayor e intermedia jerarquía, mientras que la supervisión del proceso productivo fue cubierta exclusivamente por personal de la Armnco.

Las estrategias de introducir capacitadores y personal extranjero, así como de distinguir entre obreros calificados, técnicos e ingenieros -que traslucen estos documentos- recogen las preocupaciones propias de los discursos empresarios de la época. Marcela Pronko, en su estudio comparado sobre universidades del trabajo en Argentina y Brasil, encuentra estas referencias en los discursos de los industriales. La autora los recoge desde fines de la década de 1930, e incluso en los debates parlamentarios por la creación de la Universidad Obrera Nacional (UON) en 1948, hasta en la conformación del Consejo Nacional de Educación Técnica (CONET) en 1959. ${ }^{21}$

El rol asignado a la intervención de la Armnco en la planificación y puesta en marcha de la siderúrgica mixta, abarcando desde la consecución de las herramientas financieras hasta hacerse cargo de la dirección en el despegue productivo, convive en la formulación del Plan Siderúrgico Nacional con un marcado discurso de autonomía nacionalista. Estableciéndose un contraste significativo entre la dependencia operativa de la producción y la autonomía nacional.

Este contraste es aún más visible si retomamos las afirmaciones del director de la empresa, Gral. Pedro F. Castiñeiras. Desde el título de su libro -"Esto Lo Hicieron Los Argentinos"- eligió resaltar el rol del Estado Nacional, así como el de la corporación militar y el propio, en el despegue productivo de la planta otorgándole a este evento un carácter

21 PRONKO, Marcela, Universidades del Trabajo en Argentina y Brasil. Una historia de las propuestas de su creación. Entre el mito y el olvido [en línea]. Primera edición. Montevideo: Centro Interamericano de Investigación y Documentación sobre Formación Profesional de la Organización Internacional del Trabajo [CINTERFOR/OIT], 2003. Traducción y conversión al formato HTLM de la ed.: Silvina Carrizo y Claudio Barría Mancilla. <www.inet.edu.ar/programas/formación_docente/ biblioteca/educación_trabajo/pronko.pdf $>$ [Consulta: 8 de diciembre de 2011]. 
similar a la refundación nacional. Tomamos como ejemplo el discurso inaugural al realizarse la primera colada de arrabio en el Alto Horno $\mathrm{N}^{\circ} 1$.

...Muy cerca de este lugar, hace poco más de un siglo, se llevó a cabo el acuerdo de San Nicolás que posibilito establecer ciertas bases para la organización nacional; hoy ha de permitírseme que declare enfáticamente que esta ceremonia que estamos realizando significa echar bases para la consolidación económica del país y por consiguiente, como aquel acontecimiento, también este ha de ser recogido por la historia, porque señala un hecho trascendente del quehacer argentino...22

El sostenimiento del discurso nacional en el Plan Siderúrgico, así como la exaltación nacionalista de Castiñerias, dejan en un segundo plano el significativo rol del capital trasnacional en la conformación y despegue productivo de la empresa. La participación de la Armnco en la definición de un perfil técnico para los empleados, su injerencia en la capacitación/formación de la mano de obra como en la conformación de sus primigenios procesos productivos, implicaron un alto grado de dependencia respecto del capital trasnacional. El reconocimiento implícito de esta dependencia incluía estrategias para subsanar la relativa ausencia de calificación de la mano de obra a mediano y largo plazo, mediante la puesta en marcha de diversos dispositivos de capacitación. Este objetivo comenzó a abordarse, a partir de la capacitación del personal jerárquico en el exterior y de los mandos medios y personal de línea, 'al calor' del desarrollo de la planta industrial.

\section{Alternativas de la capacitación al calor de la producción. Del despegue de la planta industrial al fin de su primera expansión}

Desde su inauguración oficial en noviembre de 1960 hasta el fin de su primera expansión productiva, en junio - julio de 1966, en las "Memorias y Balances" se detallaban la construcción, instalación y puesta en marcha de las diferentes secciones de la planta industrial, relacionándolas con el cumplimiento de los planes de expansión. La rememoración de los inicios productivos por parte de los trabajadores, recupera una visión caótica, donde confluía la necesidad de comenzar a producir, con la velocidad del emplazamiento de las principales secciones.

22 "Discurso del presidente de la sociedad mixta siderurgia argentina, en el acto de inauguración de la planta General Savio" en CASTIÑIERAS, Pedro Francisco, Esto Lo Hicieron..., Op. Cit., p. 195, (Anexo II). Un análisis del rol que juega el discurso de la soberanía, el industrialismo y el desarrollo nacional en la estructura de las relaciones de clase en SOMISA, podemos retomarlo del análisis de la antropología social que nos ofrece SOUL, María Julia, Las relaciones de clase y la construcción de una comunidad de fábrica en la ex SOMISA, Tesis para optar por el título de doctor en Humanidades con mención en Antropología, (Director) RENOLD, Juan Mauricio, Facultad de Humanidades y Artes, Universidad Nacional de Rosario, Rosario, 2010. 
E- ...Y cuando yo entré no había casi nada ahí. Pocas cosas había en SOMISA...

Inv.- ¿Cuándo entró usted a SOMISA?

E- ... en el año sesenta, cuando vino Frondizi a inaugurar el Alto Horno. SOMISA se hizo prácticamente toda en la época de Frondizi, los dos años o tres que duró el gobierno de Frondizi. Hasta el año sesenta y dos, duró; cuatro años. Cuando yo vine acá, no había casi nada, y cuando Frondizi se fue estaba todo armado.

Inv.- ¿Qué se había empezado a producir en ese momento?

E- Había empezado con Coquería, después siguió el Alto Horno, después acerías Siemens Martin, después vino tochos y palanquillas, laminación en caliente, laminación en frío y después hojalata.

Inv.- ¿Todo eso antes de que se fuera Frondizi?

E- Sí, sí, todo prácticamente todo... ${ }^{23}$ [Iván, Ingreso en 1960 en la División Almacenes hasta el año 1980 luego pasó al Departamento de Suministros retirándose en 1991] ${ }^{24}$

...Qué había de la planta en febrero del 1959. Se entraba por lo que hoy es portería uno, pero no es igual se entraba de frente...Ya estaba hecha la coquería, empezó a funcionar en 1960, estaba trabajando muy despacito, batería uno y dos en 1958, es lo primero que se extermino, los hornos de coque, que ahora están apagados y las van a demoler. Estaba hecho, el gasómetro grande y estaban haciendo el gasómetro chico, lo estaban terminando de hacer. Estaban haciendo las fundaciones del Alto Horno $\mathrm{N}^{\mathrm{o}} 1$. El puerto estaba casi terminado, lo que es el puerto mineralero, el puerto comercial vino después, eso estaba casi terminado. Todo estaba en construcción, había movimientos de tierra para donde vos miraras, gente a rolete todos los días... ${ }^{25}$ [José Luís, Ingreso en 1956, desde 1981 hasta 1991 fue Asistente del Jefe Sección Operativa de Laminación en Caliente]

Mientras que las alternativas sobre la capacitación aparecieron en los ejercicios económicos - contables a partir de 1961, se determinaban allí los objetivos de las políticas de capacitación sosteniendo: "la necesidad de promover el desarrollo del personal sobre bases técnicas, respondiendo a los requerimientos de los diferentes sectores, como al establecimiento de programas que incluyen principalmente el dictado de cursos." 26

23 Entrevista realizada el 06 de junio de 2001 a Iván Cuvelic.

24 Gran parte de nuestras entrevistas fueron realizadas como parte de un trabajo colectivo, guiadas en un primer momento por la preocupación del impacto que había generado los procesos de privatización y reconversión productiva en la planta Gral. Savio, en la mayoría participamos dos o tres entrevistadores. Los nombres de los entrevistados son ficticios, tanto para preservar su identidad como también porque sus opiniones y recuerdos nos interesan en tanto formaron parte del colectivo de trabajadores de la planta industrial y no como individuos.

25 Entrevista realizada el 24 de noviembre de 2001 a José Luis, González.

26 SOMISA, Memorias y Balances, 1962 - 1963, Sociedad Mixta Siderúrgica Argentina, Buenos Aires, 1976. Extracto perteneciente al título "Desenvolvimiento de la Planta Industrial", dentro de la sección de "Personal". 
Entre estos se enumeraban: los de "inducción, formación básica, ciclo preparatorio, tecnología mecánica, lubricación, lectura e interpretación de planos, electricidad básica, mantenimiento eléctrico, operador de grúas, soldadura, biomecánica, primeros auxilios, mantenimiento industrial de fábrica, y algunos cursos especializados de supervisión" Como podemos observar, la aplicación de este recurso abarcaba diversos aspectos del quehacer productivo, incluyendo desde las inquietudes más elementales hasta llegar a los niveles de supervisión. ${ }^{27} \mathrm{La}$ instrumentación de esta modalidad, es rememorada por los entrevistados con un significativo peso cuando refieren a sus propios procesos de capacitación. Incluso aparece mencionada indiferentemente de sus experiencias personales pues se la recuerda más allá de haber transitado por ella.

Y en SOMISA pasó eso, si vos necesitabas laburo no importa la idoneidad que tuvieras. Ahora, para trabajar en una empresa de esa envergadura, algo tenes que aprender: se te daban cursos... ${ }^{28}$ [Ernesto, ingresó en 1972 y fue Supervisor en Mantenimiento de Alto Horno]

Venían a dar cursos, era impresionantes los cursos que te daban, importantísimos.

Inv.- ¿Y para todos?

E- Para toda la gente. Pongamos, estaba el curso para los ingenieros, el curso para los oficiales... Vos querías hacer el curso, si querías hacerlo ibas y lo hacías. Te hacían cursos de perfeccionamiento para lo que nosotros hacíamos y el curso de seguridad... ${ }^{29}$

[Pedro ingresó en 1965 como Operario en Mantenimiento del sector Laminación en Caliente, se retiró en 1991]_

A partir de la reconstrucción que los siderúrgicos hacen sobre sus trayectorias laborales, pudimos detectar una apropiación particular de sus procesos de capacitación/formación. Advertimos la existencia de un conjunto de trabajadores que realizaron trayectorias laborales ascendentes; ingresaron como operarios o administrativos a fines de la década de 1950 o a principios de la siguiente década y se 'retiraron voluntariamente' en 1991, habiendo ocupado puestos en las jerarquías productivas. ${ }^{30}$

27 SOMISA, Memorias y Balances, 1964 - 1965, Sociedad Mixta Siderúrgica Argentina, Buenos Aires, 1976.

28 Entrevista realizada el 20 de abril de 2001 a Ernesto Ponce.

29 Entrevista realizada el 18 de agosto de 2001 a Pedro Alonso.

30 Para ver el desarrollo de los plantes de retiro voluntario durante el proceso de privatización de la empresa, se puede recurrir a ROFMAN, Alberto; PEÑALVA, Silvia, La privatización de SOMISA y su impacto en la producción y el empleo en San Nicolás, en Revista Ciclos, Instituto de Investigaciones de Historia Económica y Social, U.B.A., Buenos Aires, 1er semestre de 1995, № 8. 
Inv.- Vamos a hablar de la privatización y de la reconversión laboral y productiva, pero además de toda tu trayectoria adentro de la fábrica, donde te iniciaste, cómo te fuiste moviendo adentro.

E.- Yo ingresé en la Capital Federal cuando la sede central estaba frente al departamento de policía en 1956. No tenía la menor idea de lo que era una siderúrgica, ingresé en el departamento administrativo en la oficina de liquidación de haberes, ahí se pagaban los sueldos, después hubo una gran leva de gente joven en casa central para traer a hacer la administración en planta, me vine acá a San Nicolás, en febrero del '59... Y ahí pasé a laminación en el '61, y me fui en el '91, 30 años metido en laminación en caliente. Como entré, como operario haciendo trabajo, después fui supervisor y después los últimos diez años fui asistente del jefe de sección operativa... ${ }^{31}$ [José Luís]

Inv.- En relación a esta trayectoria, la suya en particular el ascenso, ¿cómo empezó, cómo llegó hasta jefe de división, de sección?

E- Y bueno yo arranqué en el '59, como técnico en entrenamiento, después cuando arranco el Alto Horno estaba como operador de estufa, operador de los recuperadores de calor. Entonces me tocó con el asistente del capataz norteamericano, y este asistente al poco tiempo tuvo un problema, me pusieron a mí a reemplazarlo... y quedé como asistente reemplazante... Después en el año '63, ascendí a capataz general, después cuando hubo esa reestructuración quedé como jefe de sección de Sinter, al poco tiempo me nombraron jefe de división en el año '77, pase a jefe de división hasta el '91 que terminé... ${ }^{32}$ [Manuel Ingresó en 1959, desde 1975 hasta 1991 fue Jefe de División de Altos Hornos]

Nos obstante el tránsito por las instancias de capacitación que implicó la participación en actividades prácticas como la lectura de material teórico, no habilitaban de por sí el progreso dentro de las plantillas. Una vez terminado el curso, cuando quedaba libre una vacante para un puesto o ante una reorganización productiva, los empleados debían pasar por instancias de evaluación implementadas por la sección de capacitación. Desde allí se determinaban la factibilidad o no de la promoción mencionada, como uno de los principales objetivos de la capacitación por la dirección empresaria.

Bueno como todo, empecé de abajo entrando en un sector que era laminación en frío acomodando bovinas en frío. Bueno después hice un curso y estuve en la grúa... Si vos querías cambiar de tarea, siempre a una mejor, te tomaban test, te hacían una serie de entrenamientos y de preguntas, después te daban el resultado y aprobabas o no. Eso no quiere decir que te prohibían, estaba la alternativa de poder volver, te daban la alternativa de decirte mira ahora no aprobaste, si vos te capacitas y te esmeras a lo

31 Entrevista realizada el 24 de noviembre de 2001 a José Luis González.

32 Entrevista realizada el 07 de mayo de 2005 a Manuel Tallarico. 
mejor en el próximo examen lo rendís... ${ }^{33}$ [Enrique, Ingresó en 1972 en Laminación en Frío y se retiró en 1991 en Ingeniería Industrial]

...se hacían cursos, nosotros por ejemplo al nivel de operarios instrumentamos un montón de planes de capacitación. Y había muchachos que de nivel operario, operario los llevábamos casi a un nivel técnico, a través de cursos hechos por capacitación...Y nosotros un poco la cosa era, por el hecho de estar ahí que la cosa anduviera bien... ${ }^{34}$ [Manuel]

Al evaluar los ascensos, además del tránsito por las instancias de capacitación, se consideraban los títulos y la instrucción previa al ingreso a la planta. Por lo tanto desde la Armnco, se organizaron instancias diferenciadas hacia los técnicos y personal que tenía un grado de instrucción mayor, aunque esta no fuera específica de la industria siderúrgica, organizando viajes de entrenamiento en diferentes unidades productivas en el mundo. A la vez se implementó un sistema en el suelo de fábrica, con entrenadores y supervisores norteamericanos, que se encargaban de la instrucción en el desarrollo del mismo proceso de trabajo.

La rememoración de estas experiencias, evidencia una apropiación crítica relacionada con la orientación general de la Armnco, por las deficiencias en los procesos de producción y el bajo nivel de 'profesionalismo' de quienes en concreto se hicieron cargo de llevar adelante la capacitación en el suelo de fábrica. Se incluyen en la crítica que tiñe toda la participación de la empresa yanqui, el deficiente asesoramiento en la adquisición de los equipos e instalaciones, por considerarlos obsoletos y atrasados en relación a la realidad siderúrgica mundial desde la inversión inicial.

Entonces Armco asumió ese rol de preparar al personal, mucha gente cuando se inició fue hacer preparación a Estados Unidos. Algunos, en el caso nuestro en la zona de Altos Hornos, fueron a Brasil y Chile, porque había ahí Altos Hornos funcionando. Así que todos los cursos, las preparaciones se hicieron en base a lo que esta gente indicaba. Lamentablemente dentro de lo que fue esa contratación, por ahí mandaban cualquier tipo. ${ }^{35}$ [José Luis]

Inv.- O sea que toda la primera etapa se hace de la mano de esta empresa, que es también, si no me equivoco la que diseña la instalación de todo.

E- Claro, Armnco hizo todo. Armnco tenía que aprobar todo, todos los planos, cuestiones de operación, todo, todo era supervisado por ellos... Armnco fue al principio, por lo menos en el área nuestra, fue bastante problemático la actuación. Porque que pasaba, Estados Unidos tenía una experiencia enorme y estaba muy actualizado en todo lo que era laminación, la parte de acero y laminación. En los Altos Hornos se

33 Entrevista realizada el 06 de mayo del 2001 a Enrique Ficoseco.

34 Entrevista realizada el 25 de agosto de 2001 a Manuel Tallarico.

35 Entrevista realizada el 24 de noviembre de 2001 a José Luis González. 
había quedado un poco tecnológicamente atrasada porque no le convenía renovar, tenía muchos hornos viejos que operaron mucho durante la guerra, y en general estaban al lado de explotaciones de yacimientos mineros. Entonces les costaba poco el mineral, el combustible también era barato, no le interesaba renovarse en la parte de altos hornos... Para colmo de males vinieron tipos que eran, algunos tomaban mucho, gente que allá claro... se ve que no querían venir todos acá... ${ }^{36}$ [Manuel]

...la empresa se fue ampliando, pero hubo un gran error lo que paso en caliente, porque paso en todos los sectores en diferentes momentos. No hubo renovación, no de gente, de equipos. Es decir, nosotros entramos a trabajar con equipos que ya eran viejos, el tren de laminación en caliente, con todo lo que se armó en el 61 era un tren de laminación que había sido fabricado para ser montado en Checoslovaquia en el año 39 , vino la guerra, la segunda guerra mundial y quedo todo encajonado en el puerto de Nueva York. Cuando terminó la guerra Checoslovaquia lo reclamó, pero como estaba en Europa del este, Estado Unidos no se lo mando, entonces salió a subasta pública y en subasta pública lo compró Fabricaciones Militares por chaucha y palito, y lo tuvo encajado acá hasta el 61 que se entró a fabricar, esa fue más o menos la historia de laminación en caliente. Pero era el equipo de 1939, se montó acá y para nosotros era todo nuevo, pasaron los años y no se renovaron los controles de los hornos, la primera renovación de control se hizo en el año 80, 20 años después... ${ }^{37}$ [José Luís]

La implementación de estrategias de capacitación internas y el establecimiento de trayectorias formales de ascensos dentro de la empresa, se conjugaron con una política de captación para lograr el ingreso de personal con un mayor grado de formación específica. Estas políticas concurrieron al intento de reducción en el mediano y largo plazo de la participación directa del personal extranjero, intención que estaba formulada desde el Plan Siderúrgico Nacional. A la vez significaron la preponderancia de trabajadores con un grado mayor de instrucción a su ingreso en relación al conjunto del plantel.

La progresión sobre el ingreso de profesionales en los ejercicios contables de los años 1964, 1965 y 1966, permite observar un aumento de su peso relativo y la disminución de los técnicos extranjeros.

En las "Memorias y Balances", bajo el ítem "Profesionales Universitarios" se observa un incremento que casi triplica su ingreso: en 1964 había 79 profesionales, en 1965 ingresaron 29 más y 1966 ingresaron nada menos que 105 llevando el número total a 215 profesionales universitarios. Mientras que la progresión para los "Técnicos Extranjeros" evolucionó de forma inversamente proporcional, reduciendo su cantidad a menos de la mitad ya que en 1964 había 38, cantidad que dos años luego se reduce a solo 17 de su tipo. ${ }^{38}$

36 Entrevista realizada el 25 de agosto de 2001 a Manuel Tallarico.

37 Entrevista realizada el 24 de noviembre de 2001 a José Luis González.

38 SOMISA, Memorias y Balances, 1963 - 1964, 1964 - 1965, 1965 - 1966, Sociedad Mixta Siderúrgica Argentina, Buenos Aires, 1976. 
Al comparar esta evolución con el ingreso del resto de los empleados, se hace aún más notable la contratación de personal con un grado mayor de instrucción profesional. En el resto de los ítems en ningún caso se supera el 50\% que actuaba, en 1963- 1964 entre los "Técnicos Sub.-profesionales, Empleados Administrativos y Auxiliares" el ingreso es de alrededor del 45\%, los "Capataces y Supervisores" incrementan su número en un 25\% y la participación de los "Operarios" aumenta tan solo en un 10\%. En estos últimos tres años del período en observación, fue en las categorías de mayor calificación donde se efectuaron los ingresos porcentualmente más numerosos.

Entendemos que esta situación es indicativa de las transformaciones productivas iniciadas, destacándose la necesidad de potenciar la productividad de la planta para concretar el plan de las 1.100.000 toneladas en lingotes de acero/año. ${ }^{39}$ Esta ampliación implicó también la diversificación productiva, con el agregado de nuevas líneas de producción y el mejoramiento de la calidad de los bienes. Este nuevo personal técnico, se encargó de concretar tareas especializadas propias de la expansión.

...el aumento de la fuerza efectiva alcanza a 410 personas, o sea el $5,2 \%$ con respecto a la totalizada en el cierre del ejercicio anterior. La causa del incremento radica en la circunstancia de haberse habilitado la línea de estañado electrolítico, por un parte, y en el completamiento de la mano de obra por otra; además, al hecho de haber incorporado un importante números de técnicos - particularmente de profesionales universitarios- con destino a seguir los cursos de capacitación iniciados por la empresa con el propósito de proveerles la información y prácticas necesarias, para asumir la dirección de los nuevos equipos a instalar con motivo de los planes de expansión... ${ }^{40}$

La opción de haberles otorgado a los profesionales universitarios de reciente ingreso la dirección de los equipos a instalarse, nos brinda la pauta de la constante necesidad de incorporar empleados con un grado mayor de instrucción previa, que deberán foguearse en la producción a los fines de concretar las metas proyectadas. La participación de los órganos técnicos de la empresa, en la primera expansión productiva a solo seis años de la puesta en marcha, nos proporciona una idea de cierto grado de efectividad de las políticas llevadas adelante. Aunque esta expansión, según lo que apreciamos en las "Memorias y Balances" y en "Esto Lo Hicieron los Argentinos", se concretó según el sistema "Llave en Mano". Esto implicaba que las tareas de montaje y construcción de los nuevos equipos las realizaron empresas trasnacionales contratadas a este fin, dependiendo de ellas también la

39 "Durante el presente período se completaron los estudios de las propuestas recibidas en concursos de precios internacionales a los fines de concretar el plan oportunamente anunciado de llevar la producción de la Planta Gral. Savio a 1.100.000 toneladas de lingotes de acero por año. Al cierre del ejercicio estaban colocadas las órdenes para la adquisición de los equipos y montajes que integran el programa propuestos..." SOMISA, Memorias y Balances, 1964 - 1965 ..., Op. Cit., p. 21.

40 SOMISA, Memorias y Balances, 1965 - 1966..., Op. Cit., p. 18. 
ingeniería de detalle. Por lo tanto, la independencia técnica en el crecimiento de la producción siderúrgica proclamada por el director de la empresa, y sostenida en las "Memorias y Balances", es aún bastante relativa para 1966, sobre todo en las tareas de ingeniería básica sobre las que se asienta la expansión de la planta industrial.

\section{Reflexiones finales}

El problema de la calificación del personal para el desarrollo de la primera unidad productiva siderúrgica a ciclo integral, aparece formulado desde el Plan Siderúrgico Nacional. Algunas de las alternativas con las que allí se lo considera, fueron puestas en práctica en el despegue productivo de la Sociedad Mixta Siderurgia Argentina. Al analizar su formulación en los documentos que proyectó la empresa, así como en los seis primeros ejercicios económico-contables, dimos cuenta del rol trascendental que jugó el capital trasnacional en la capacitación de los siderúrgicos, y su convivencia con un discurso de marcado sesgo nacionalista del desarrollo industrial.

Desde 1960 a 1966 a la par de la expansión productiva de la planta Gral. Savio, observamos la puesta en práctica de diferentes dispositivos para adiestrar al personal y la incorporación de empleados con un grado mayor de instrucción. Este paulatino proceso de nacionalización de la capacitación, permitió una independencia relativa de los órganos técnicos de la empresa, que pudieron hacerse cargo de las tareas propias de su primera expansión productiva que se consideraba finalizada en 1966. Estas transformaciones sumadas al cumplimiento de sus metas, como la diversificación y el aumento en el volumen de la producción, otorgando un nuevo impulso al sector siderúrgico, son demostrativos de cierta efectividad de las políticas de capacitación implementadas.

Si bien con una apropiación crítica respecto de la capacitación en los inicios productivos, y aún más conflictivos en relación a la participación integral de la Armnco en la empresa, para los primeros 'somiseros', la capacitación habría jugado un rol significativo en su identificación con la marcha de la empresa. En lo individual la asocian con las habilidades adquiridas que, junto con la estabilidad en el empleo, les permitieron realizar trayectorias laborales ascendentes, llegando en algunos casos a las jerarquías dentro de la pirámide de mandos. En lo colectivo, la capacitación habría aportado a largo plazo las bases técnicas necesarias para el sostenimiento de la producción siderúrgica.

Los viajes al exterior, la participación de capacitadores extranjeros en el suelo de fábrica, la implementación de cursos, la conformación de una sección encargada de la capacitación y evaluación de la formación, la incorporación de profesionales con mayor instrucción previa, aparecen como las estrategias utilizadas por la dirección empresaria para capacitar a su personal. Estas, junto con la adquisición de los conocimientos propios de ensayo y error, comunes a todos los procesos productivos, fueron los dispositivos que habilitaron la incorporación de saberes necesarios para sostener la producción durante el caótico despegue de la planta industrial. 
A la vez, esas alternativas consolidaron el proceso de nacionalización de la capacitación, permitiendo la identificación de los trabajadores con la empresa. También habilitaron a los trabajadores a rememorar el paso por la gestión estatal de la empresa, con un marcado contraste respecto de la actual gestión privada, concretada en el momento inmediatamente anterior a nuestras indagaciones sobre su historia. Sostenemos que la reconstrucción que los trabajadores hacen sobre sus procesos de capacitación, es un elemento que les permite reforzar su identificación con la SOMISA estatal.

El inédito despegue de una planta industrial de estas características implicó nuevos problemas, que no eran ajenos a la profundización del proceso de industrialización sustitutivo de importaciones. La posibilidad de poder observar la formación de un conjunto de siderúrgicos a partir de las transformaciones en la empresa, suponen desentrañar detalladamente la conformación de los diferentes procesos productivos y los requerimientos para cada puestos, así como sus transformaciones. La necesidad de extender la mirada hacia fuera del propio ámbito de la empresa, para observar el desarrollo del sistema educativo, así como indagar las funciones e intervenciones del paulatino proceso de profesionalización de quienes fueron ocupando los puestos directivos claves dentro de la empresa, aparecen como los lineamientos principales que guiarán nuestras indagaciones en el futuro.

Recibido: 06/05/2013

Aceptado: 15/08/2013 